\title{
Analysis of the Influence of Contamination in Lubricant by Biodiesel in a Pin-On-Disk Equipment
}

\author{
Murilo Parra Cuerva ${ }^{a}$, Aparecido Carlos Gonçalves ${ }^{b *}$ (D), \\ Maria da Consolação Fonseca de Albuquerque ${ }^{c}$, Fábio Roberto Chavarette ${ }^{d}$ (D), \\ Roberto Outa ${ }^{e}$ (D), Estevão Fusaro de Almeida ${ }^{b}$ \\ ${ }^{a}$ Centro Universitário Votuporanga - UNIFEV, R. Pernambuco, $n^{\circ} 4.196$, Votuporanga, SP, Brasil. \\ ${ }^{b}$ Universidade do Estado de São Paulo - UNESP, Departamento de Engenharia Mecânica, \\ Ilha Solteira, SP, Brasil. \\ ${ }^{c}$ Universidade do Estado de São Paulo - UNESP, Departamento de Engenharia Civil, \\ Ilha Solteira, SP, Brasil. \\ ${ }^{d}$ Universidade do Estado de São Paulo - UNESP, Departamento de Matemática, \\ Ilha Solteira, SP, Brasil. \\ ${ }^{e}$ Faculdade de Tecnologia de Araçatuba - FATEC, Departamento de Biocombustíveis, \\ Araçatuba, SP, Brasil.
}

Received: July 20, 2021; Revised: October 21, 2021; Accepted: October 31, 2021

\begin{abstract}
The introduction of biodiesel to commercial diesel is being increased every year. The need to check this addition to the engine and lubricant is important for automakers and internal combustion engine manufacturers. The oil analysis technique is a type of predictive maintenance, done by collecting oil from equipment and analyzing it later in the laboratory, or by analyzing it directly and continuously in on-line systems. In internal combustion engines, all parts have a pre-established service life, longer or shorter, according to the specific function assigned to it. By analyzing the oil, the condition of these parts can be monitored. The oils analysis reveals the first signs of wear of a component. The identification is made based on the study of the number of particles, size, shape and composition thereof, present in the lubricant samples, which provide accurate information about the conditions of the moving surfaces without the need to disassemble the assembly to which these parts belongs. In this work a lubricant contamination by biodiesels were made to simulate possible scenarios within an internal combustion engine.The lubricant recommended by an engine manufacturer was "contaminated" with commercial diesel and with different percentages and types of biodiesel. After this "contamination" they were placed in a pin on disk device under certain conditions. Through the analyzes of the lubricants extracted from the Pin on disk Equipment after the tests, some analysis were carried out in order to study the effects of using biodiesel in the internal combustion engine. These analyzes consisted of Flash point, analytical ferrography, monitoring of ferrous particles generated, viscosity, viscosity index, basicity index and X-ray spectrometry.Among the results obtained it is observed that for a 5\% contamination of animal biodiesel there was an increase in the viscosity index. Conversely, the contamination of $5 \%$ of animal + vegetable biodiesel decreased the viscosity index in relation to Diesel B5. We also found that these biodiesel additions were not detrimental to the engine and lubricant at the mix ratios and test conditions used.
\end{abstract}

Keywords: Predictive maintenance, Biodiesel, Wear particles, Lubricant analysis, Diesel internal combustion engines, PIN-ON-DISK

\section{Introduction}

With the increase in air pollution and greenhouse gases, a global concern is the discovery of new energy sources that emit less harmful gases to the environment, reducing or delaying the effects of global warming. Thus, Biodiesel has some properties that are more beneficial. According to Knothe $^{1}$, biodiesel has a higher flash point, higher lubricity and no sulfur compounds.

*e-mail: aparecido.carlos@unesp.br
Thus, this research was motivated due to the increased use of these new energy sources instead of fossil sources, such as Biodiesel, since there is a lower pollution rate with the use of it. With its increasing use, there is concern about its influence on the frictional parts of an internal combustion engine, as according to Booser ${ }^{2}$, fuel can enter the crankcase through various possibilities such as rings, pistons, leaks at injection seals, hoses, or pump.

Oil analysis is paramount in predictive maintenance, as it allows the identification of the part condition, through 
the wear particles geometry, number of particles in the oil and their chemical composition, allowing identifying which engine member suffer wear and how severe it is.

The most important tests in lubricant analysis are Viscosity, Viscosity Index, Flash Point, TBN (Total Base Number), TAN (Total Acid Number), analytical and direct ferrography, water concentration, and dispersion testing, magnetic particle index and x-ray spectrometry among others.

This paper presents a contribution to the analysis of the effect of the biodiesel addition to conventional diesel through the verification of wear in a pin on disk equipment. This equipment simulates the engine parts wear.

The novelty is the contamination of the lubricant, used in an internal combustion engine, with a variety of biodiesel in order to check their effect inside the engine through pinon-disk test. Lubricant analysis shows whether the addition of biodiesel to the diesel alters the health of this lubricant. Particle analysis shows the effect of these additions on the internal condition of the engine.

\section{Background}

Several studies have been done in an attempt to verify the influence on the engine of the contamination of the lubricant by biodiesel. Such work ranges from wear checking (on equipment that simulates engine parts) to physicalchemical testing for analysis of lubricant deterioration by these contaminants.

Shanta et al studied the contamination of biofuels in mineral oil, targeting the aspect of tribology and wear study. For this purpose, an AISI 1018 steel disk and an AISI 316 stainless steel pin were used to mount the test equipment, the pin-on-disk. The mineral oil that was used in the experiment was $15 \mathrm{~W} 40$ and the contaminating biofuels were canola oil, peanut oil, soybean oil and chicken fat oil. The results show that the types of contaminants used has the same effect in wear compared to normal diesel fuel, depending only on the percentage of contamination. Through the experiment, Shanta et al. ${ }^{3}$ also concluded that contamination by animal biodiesel was less harmful compared to the vegetable biodiesels used in the tests.

Castro $^{4}$ studied the wear mechanisms in a two-material pin on disk equipment, SAE 1045 steel and SAE 52100 steel in the presence of $100 \%$ soybean biodiesel, $50 \%$ regular diesel and 50\% soybean biodiesel, and finally, 93\% regular diesel and 7\% soybean biodiesel. The study found that all wear mechanisms were abrasive, for SAE 1045 steel the best wear resistance was $100 \%$ biodiesel, followed by $50 \%$ and then $7 \%$ biodiesel. SAE 52100 steel had the same characteristics. Indicating the correlation between contamination index and wear.

Fang et al. ${ }^{5}$ through testing the samples in a "Four Ball" equipment, indicates that at first the wear of the parts using vegetable biodiesel contamination tends to fall, but with the biodiesel aging, there is an increase of the wear rate even to concentrations less than $5 \%$.

Thornton et al. ${ }^{6}$ also evaluated the influence of biodiesel blending on engine lubricating oil, showing that biodiesel blending increased oxidation, which resulted in a reduction in oil TBN
According to Booser ${ }^{2}$, the contamination of fuel in the lubricant causes a decrease in its viscosity. A variation of $5 \%$ to $10 \%$ in the viscosity of the oil implies a deficit in the lubrication process, which can cause serious risk to the lubricated parts.

For Lockwood and Dalley ${ }^{7}$, a variation greater than $3 \mathrm{mg}$ / $\mathrm{g}$ in the original TBN measurement of the lubricating oil also entails a need for machine shutdown and subsequent root cause investigation. Since some oxidized components resulting from fuel combustion are mixed in the lubricating oil, its result in an increase of TAN and a decrease in TBN. They also say that progressive advances in instrumentation permit the study and wide classification of the wear particles produced by many different metals and substances.

For Gonçalves et al. ${ }^{8}$, the flash point serves as a measurement of the lubricant oil contamination, as the higher the fuel oil contamination, the lower the flash point will be relative to new oil.

The dispersion test acts to quantify the dispersion additive in the sample. If dispersion additives cannot reach a minimum value, which is indicated by a mark on a special paper placed in contact with the lubricating oil, the lubricating oil may be unable to reach all places required for lubrication of the assembly parts, as explained in Gonçalves and Padovese 9 .

Ferrography is divided into two parts, quantitative ferrography and analytical ferrography.

Quantitative ferrography is the quantification of the size and number of particles suspended in the lubricating oil. This technique provides information on the degree of wear severity present in the object to be analyzed through continuous monitoring, usually seen through a trend line.

For Gonçalves and Padovese ${ }^{10}$ when the trend lines from the analytical ferrography indicates that there has been some deviation, it is necessary to analyze analytically the particles present in the sample of the lubricating oil.

The analytical ferrography examines the size of the wear particle, its concentration, the color and the shape. Thus, it is possible to determine the modes of wear and its causes. For this analysis, the RPD (rotary particle depositor) equipment and a ferroscope are used for the visualization and characterization of the wear particles.

Seeking to evaluate biodiesel mixtures in vehicles, Schumacher and Gerpen ${ }^{11}$ monitored the mixture of 0,1 , 2 and $100 \%$ of Soy Methyl esters in 5.9-liter engines. The work aimed to evaluate the behavior of the original engines of the factory with the partial biodiesel mixtures. In addition, the spectrum analysis was performed without lubrication at the end of the measurement and with the amount of elements present in the lubrication. As a result, levels of aluminum, iron, chromium and lead were selected lower than those compared to engines using ordinary diesel.

Fitch $^{12}$ discussed the methods used by specialists in the counting of particles present in the used oils of internal combustion engines. Some applied methods were commented on, such as the dilution of the lubricant used with solvent, or with another automotive fluid, or with clean hydraulic fluid with subsequent passage of the lubricant through membranes of known porosity. It was concluded that, despite the little application by the laboratories, the trend is the use of particle counting in internal combustion engines, regardless of the 
method, what matters is the trend of the measured numbers and not the absolute value, because each method employed has a value.

Geach $^{13}$ researched an automatic method to measure the dilution of oils from internal combustion engines by fuel, using the gas chromatography technique. The samples were injected into the system automatically, through a system and software connected to a computer installed on the chromatograph data acquisition board.

Outa et al. ${ }^{15}$ developed a methodology that classifies signals into groups of faults and normal signals, using algorithms from artificial immune systems. He claims that this system has several applications with the possibility of wear tests on pin on disk equipment.

Barsari and Shirneshan ${ }^{16}$ investigated the wear characteristics of biodiesel derived from sunflower and soybean oil. Five mixtures were tested for 1500 and 3600 seconds at four different rotations $(600,900,1200$ and $3600 \mathrm{rpm})$ in a Four Ball equipment. They used an optical microscope to observe the wear on the surfaces of the spheres of the Four Ball apparatus. The results indicated that wear and friction were reduced with increasing rotation. It found that for an increased concentration of biodiesel friction and wear were reduced at lower revs due to free fatty acids, monoglycerides, and diglycerides. At higher speeds, friction and wear increased due to the reduction in viscosity due to the oxidation formed during the exposure of biodiesel to high temperatures. The authors concluded that B100 has better lubricity compared to other blends at low rotation, and that B20 performs better at high rotation.

Khorshidnia and Shirneshan ${ }^{17}$ employed a four-ball tester to study the effects of copper oxide nanoparticle additions on the lubricating behavior of biodiesel-diesel fuel blends.

At four distinct rotational speeds of 600,1200 , and 1500 $\mathrm{rev} / \mathrm{min}$, three fuel blends with additions of $0,25,50$, and 75 ppm nanoparticle were tested in steady-state circumstances. Because of the nanoparticles filling the friction surface and replacing sliding friction with the rolling effect in the contact zone, the friction coefficient lowers with increasing nanoparticle concentration up to $50 \mathrm{ppm}$. The friction coefficient, on the other hand, was greatly improved when 75 ppm nanoparticles were added to fuel blends B10 and B20. However, the lubrication of fuel mix B50 with 75 ppm nanoparticle is superior than that of other fuel blends in the same condition, according to the findings. Furthermore, free fatty acids, monoglycerides, and diglycerides, which are all components of biodiesel, were found to reduce the friction coefficient as the content of biodiesel increased.

Barsari and Shirneshan ${ }^{18}$ studied friction characteristics of biodiesel (mixture of sunflower and soybean methyl ester) by using a four-ball wear testing machine. Under the run-in period conditions, the results showed that increasing rotational speed reduced friction. Furthermore, the results revealed that when the quantity of biodiesel in the fuel blend grows, the friction coefficient reduces at rotational speeds of 600 and $900 \mathrm{rpm}$. This is owing to biodiesel's increased viscosity and the inclusion of free fatty acids, monoglyceride, and diglyceride components, which improve the lubricity qualities of fuel mixes. However, because of reduced fuel viscosity, oxidation, and moisture absorption at a higher temperature environment, the coefficient of friction of the gasoline blends that contained more biodiesel (B50 and $\mathrm{B} 100)$ rose at rotational speeds of 1200 and $1500 \mathrm{rpm}$. As a result, it was determined that B20 has superior tribology performance at greater rotational speeds.

\section{Materials and Methods}

The wear tests were performed on the Pin on disk equipment shown in Figure 1 and detailed in Figure 2.

The cups (disks) were done by $\mathrm{ABNT}^{14} 8640$ steel and the pins by ABNT 4140 steel.

ABNT 8640 is a Nickel-chromium-molybdenum steel with $0.55 \% \mathrm{Ni} ; 0.5 \% \mathrm{Cr} ; 0.20 \% \mathrm{Mo}$ and $0.4 \% \mathrm{C}$.

ABNT 4140 is a Chromium-molybdenum steel with 0.50 to $0.95 \% \mathrm{Cr} ; 0.12$ to $0.30 \%$ Mo and $0.40 \% \mathrm{C}$.

Pin and disk roughness were measured using the Mitutoyo Rugosimeter, model: SJ-201P. The measurements were made in three different regions on the disk and in three different directions on the pin; the measurement to be considered
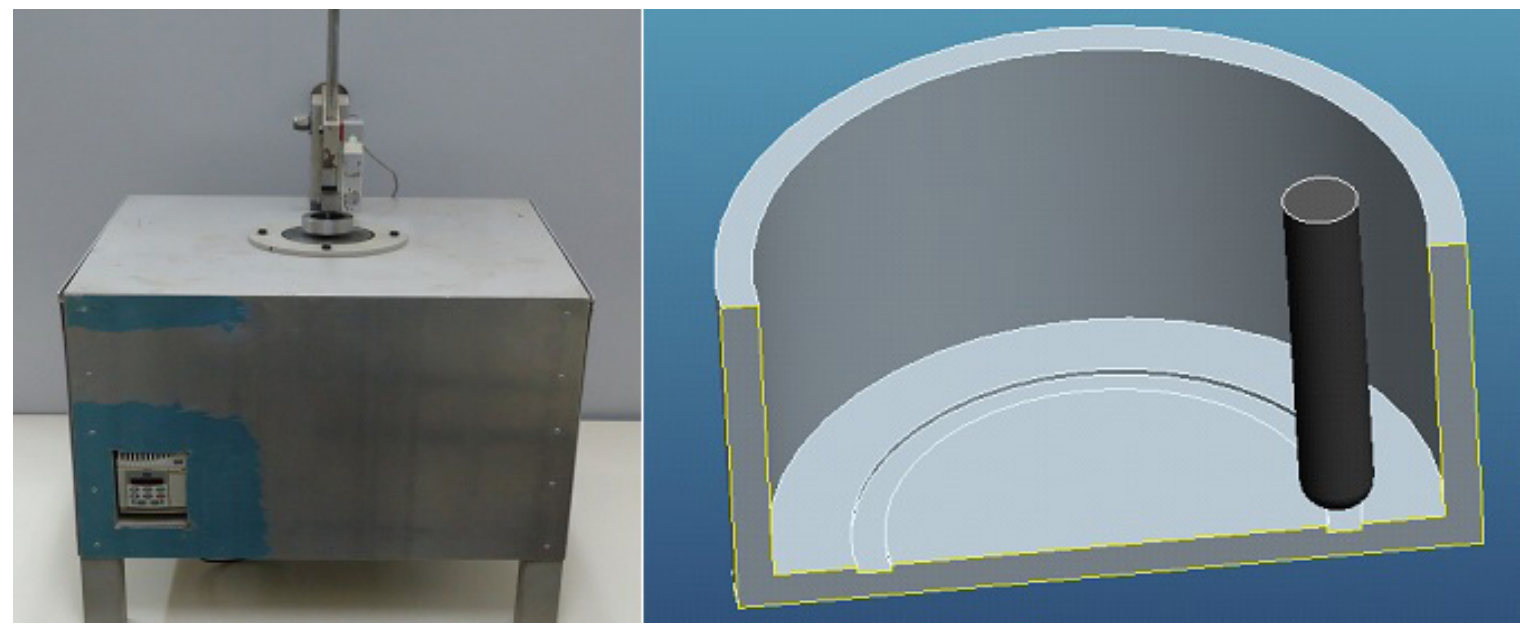

Figure 1. Pin on disk equipment. 
comes from the average of these three measurements. Table 1 shows the results of roughness.

Four types of contaminants were used for lubricating oil: Regular B5 Diesel, Vegetable Biodiesel (Sunflower), Animal Biodiesel (fat) and a blend of Vegetable and Animal Biodiesel.

The tests were performed with two different concentrations of $2 \%$ and $5 \%$ biodiesel in the lubricating oil. Under the test conditions, the linear speed of $1 \mathrm{~m} / \mathrm{s}$ and a load of 5 $\mathrm{kg}$ were used. Figure 3 illustrates the configurations of the tests performed.

The tests simulated 4 kilometers (sliding length of 4,000 $\mathrm{m}$ ) each, taking a time of 1 hour and 6 minutes.

Rotations were monitored by a tachometer brand Oppama Pet model - 2000 DX.

The lubricant used to lubricate the experimental artifact (which has been contaminated by biodiesel) is classified as API CF SAE 40. Table 2 describes the physical-chemical properties of the lubricant used.

The lubricating oil after Pin on disk testing was collected for analysis. One such analysis is analytical ferrography where the preparation of the blades occurs on a rotary ferrograph. In the apparatus the particles are deposited on a glass slides (ferrogram) forming three concentric rings. The rings are relative to the size of the particles, with larger particles $(50-200 \mu \mathrm{m})$ deposited in the inner ring, medium $(10-50 \mu \mathrm{m})$ in the middle ring and small particles $(1-10 \mu \mathrm{m})$ in the outer ring.

The fixation of the particles is made by the action of magnetic, centrifugal and gravitational forces.

The obtained ferrogramas were also exposed to 330 ${ }^{\circ} \mathrm{C}$ for 90 seconds. Figure 4 shows one of 12 ferrograms obtained by the rotary particle separator.

These ferrograms were analyzed in a ferroscope brand OLYMPUS model BX 41.

For the analysis of ferromagnetic particles, the PQA (particle quantifier analysis) ferrous particle monitor was used. This equipment is a magnetometer with two coils arranged so that the coil located on the sample part (sensor) and the reference coil are in equilibrium when there is no sample on the sensor or external electromagnetic interference. The
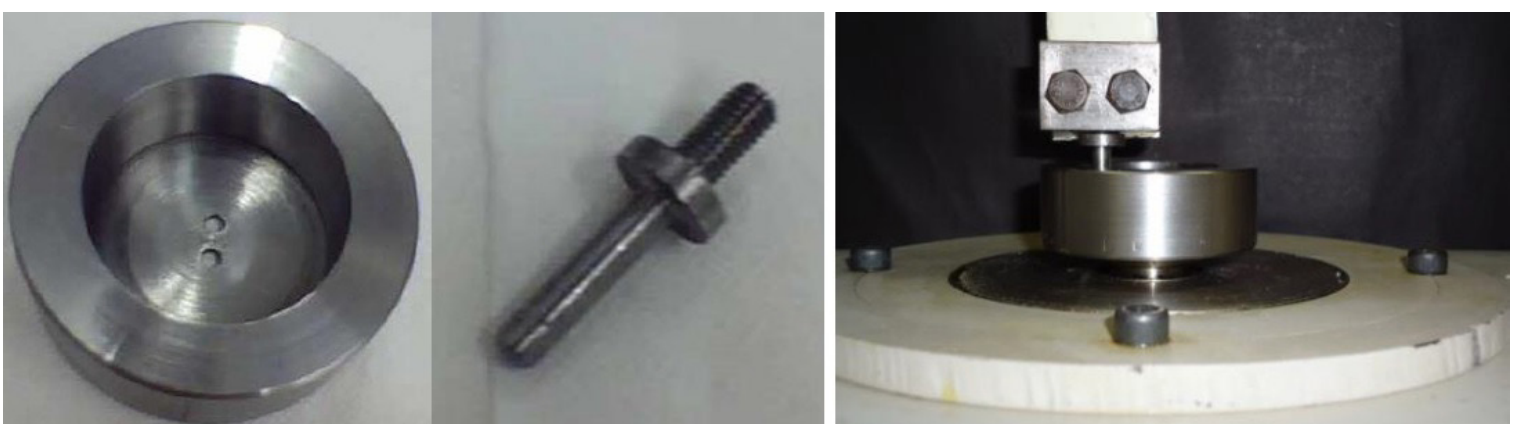

Figure 2. Cup-shaped disk made of SAE 8640 steel, SAE 4140 steel pin and apparatus assembly.

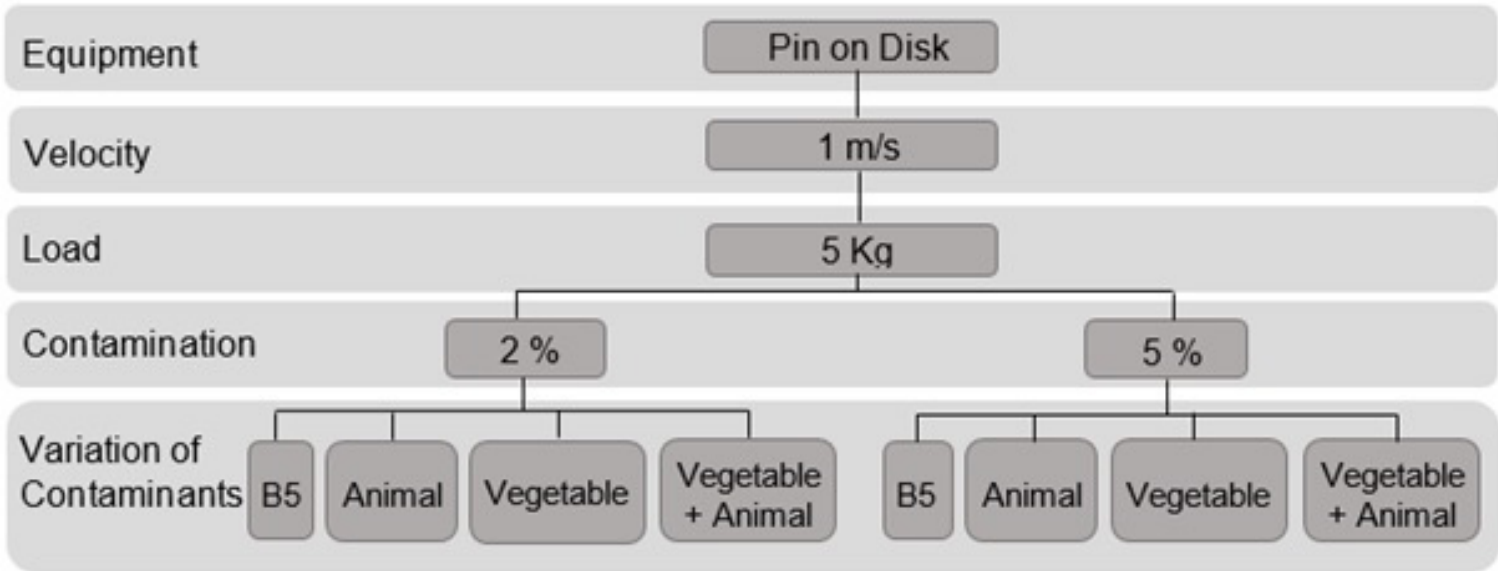

Figure 3. Tests Variations. Source: Author's own elaboration.

Table 1. Measurements and average values of disk and pin roughness.

\begin{tabular}{ccccc}
\hline & Measurement $1[\mu \mathrm{m}]$ & Measurement $2[\mu \mathrm{m}]$ & Measurement $3[\mu \mathrm{m}]$ & Medium roughness $(\mathrm{Ra})[\mu \mathrm{m}]$ \\
\hline Disk & 4.19 & 4.25 & 4.58 & 4.34 \\
\hline Pin & 1.85 & 1.99 & 1.81 & 1.88 \\
\hline
\end{tabular}

Source: Author's own elaboration. 


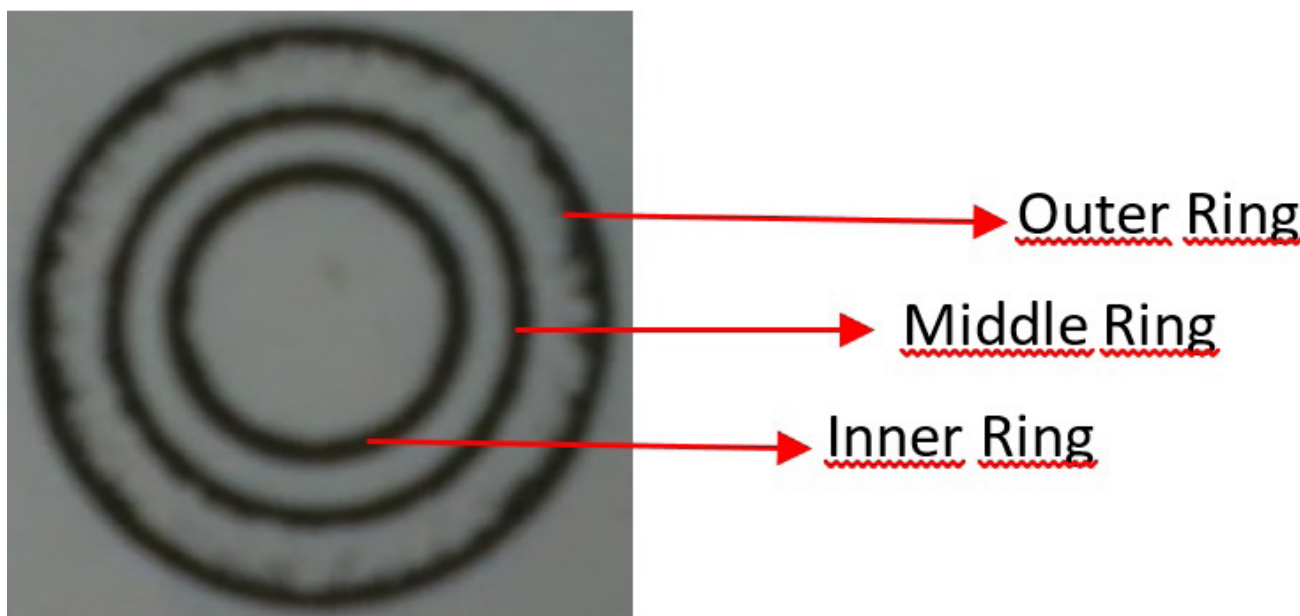

Figure 4. Slide obtained by RPD assay. Source: Author's own elaboration.

system is carefully designed to ensure that both coils also respond equally to temperature changes in the environment. The resulting signal caused by the imbalance is amplified, filtered, and displayed as an "index" PQ (particle quantifier). It relates directly to the mass of the ferromagnetic particles in the sample.

Subsequently, the viscosity in the Saybolt viscometer was measured at $40^{\circ} \mathrm{C}$ and $100^{\circ} \mathrm{C}$. Ten measurements were made and the averaged of them was used to calculate the viscosity index.

The experimental test for the flash point was performed in a Cleveland open vessel.

The TBN analysis was performed according to $\mathrm{ABNT}^{20}$ by potentiometric method. The device used was the Hanna 902 titrator from Hanna. Titration indicates whether contamination of the lubricating oil by Biodiesels influences the acidity of the lubricant, decreasing the TBN number.

To find out which elements are present in the lubricating oil, was used the x-ray spectrography technique, and the apparatus used was the "Oxford" X-ray Spectrometer model "X-Supreme".

The dispersion test was done by the tape method, thus the lubricant is efficient if after contact with the lubricant and after 24 hours of this contact, it reaches a demarcation on the upper edge of the tape.

\section{Results and Discussion}

Table 3 shows the results of viscosities for contaminated lubricants.

Through analysis of the viscosity at $40^{\circ} \mathrm{C}$ and $100^{\circ} \mathrm{C}$ was calculated viscosity index testing for each variation. It was found that the higher the contamination, the lower the viscosity of the lubricant. This effect coincides with that expected in the literature, since biodiesel is less viscous. Figure 5 shows the viscosity index calculated.

Through the above figure, it is possible to obtain a better comparison of the results. It is noted that for animal biodiesel the higher the contamination, the higher the viscosity index, while for the remaining contamination the results differ from
Table 2. Physical-chemical properties of the lubricant API CF SAE 40.

\begin{tabular}{lc}
\hline \multicolumn{1}{c}{ Brand } & \multicolumn{2}{c}{ Petrobras $^{19}$} \\
\hline Model & $\begin{array}{l}\text { Lubrax MD-400 API CF } \\
\text { SAE 40 }\end{array}$ \\
\hline Flash point $\left({ }^{\circ} \mathbf{C}\right)$ & 262 \\
\hline Pour point $\left({ }^{\circ} \mathbf{C}\right)$ & -6 \\
\hline Viscosity $\left(\mathbf{4 0}^{\circ} \mathbf{C}\right)[\mathbf{c S t}] /[\mathbf{S S U}]$ & $163.5 / 757.6$ \\
\hline Viscosity $\left(\mathbf{1 0 0}{ }^{\circ} \mathbf{C}\right)[\mathbf{c S t}] /[\mathbf{S S U}]$ & $15.46 / 71.6$ \\
\hline Viscosity index & 95 \\
\hline Sulphated ashes $(\mathbf{\%}$ weight) & 1.18 \\
\hline Total Base Number $(\mathbf{m g K O H} / \mathbf{g})$ & 11.4 \\
\hline
\end{tabular}

Source: ${ }^{19}$.

Table 3. Saybolt Viscosity Values for Each Contamination Type.

\begin{tabular}{lccc}
\hline \multirow{2}{*}{ Lubricating oil } & \multirow{2}{*}{ Contamination } & \multicolumn{2}{c}{ Saybolt Viscosity } \\
\cline { 2 - 4 } & & $40^{\circ} \mathrm{C}$ & $100^{\circ} \mathrm{C}$ \\
\hline \multirow{2}{*}{ Biodiesel B5 } & $2 \%$ & 642.3 & 79.3 \\
\cline { 2 - 4 } & $5 \%$ & 503.9 & 68.1 \\
\hline Vegetable Biodiesel & $2 \%$ & 559.5 & 78.5 \\
\cline { 2 - 4 } (Sunflower) & $5 \%$ & 501.2 & 72.0 \\
\hline Animal Biodiesel & $2 \%$ & 665.9 & 83.2 \\
\cline { 2 - 4 } (Fat) & $5 \%$ & 557.7 & 72.5 \\
\hline Biodiesel Animal + & $2 \%$ & 620.2 & 88.6 \\
\cline { 2 - 4 } Vegetable & $5 \%$ & 496.3 & 69.8 \\
\hline
\end{tabular}

the first, showing that the higher the contamination the lower the viscosity index.

Figure 6 shows one of the results of the dispersion tests.

From the Figure 6, it is verified that the dispersion additive is present and active and was not depleted. This has occurred for all contaminations.

The particles, found for each test variation and separated in each ferrogram, were photographed by ferroscope. The most salient particles in the ferrograms are shown in Figure 7 to Figure 10.

> Contaminated with B5 Biodiesel (regular).

- Load with the weight of $5 \mathrm{Kg}$ and $\mathrm{V}=1 \mathrm{~m} / \mathrm{s}$ 


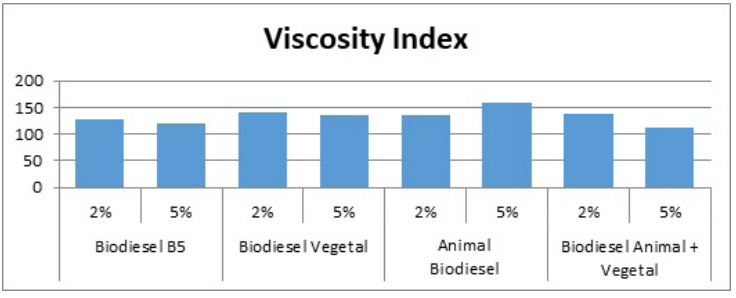

Figure 5. Comparison of viscosity indexes.

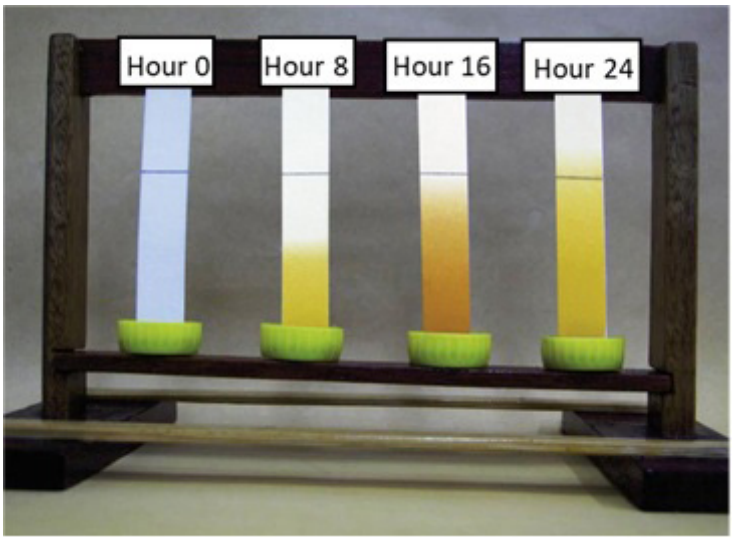

Figure 6. Dispersion test for all contamination.

\section{> Contaminated with Animal Biodiesel.}

- Load with the weight of $5 \mathrm{Kg}$ and $\mathrm{V}=1 \mathrm{~m} / \mathrm{s}$

\section{$>$ Contaminated with Vegetable Biodiesel.}

- Load with the weight of $5 \mathrm{Kg}$ and $\mathrm{V}=1 \mathrm{~m} / \mathrm{s}$

$>$ Contaminated with Animal and Vegetable Biodiesel.

- Load with the weight of $5 \mathrm{Kg}$ and $\mathrm{V}=1 \mathrm{~m} / \mathrm{s}$

It is observed in this analysis, normal wear for all pictures (Figure 7 to 10). There are some oxides particles (indicated by the arrows) that is normal occurrence when in small amount. There is no evidence of excessive wear.

Figures 11 to 14 show the results obtained with blades heated to $330^{\circ} \mathrm{C}$ for 90 seconds. The most salient particles in the ferrograms are shown.

> Contaminated with B5 Biodiesel (regular).

- Load with the weight of $5 \mathrm{Kg}$ and $\mathrm{V}=1 \mathrm{~m} / \mathrm{s}$

$>$ Contaminated with Vegetable Biodiesel.

- Load with the weight of $5 \mathrm{Kg}$ and $\mathrm{V}=1 \mathrm{~m} / \mathrm{s}$

> Contaminated with Animal Biodiesel.

- Load with the weight of $5 \mathrm{Kg}$ and $\mathrm{V}=1 \mathrm{~m} / \mathrm{s}$

$>$ Contaminated with Animal and Vegetable Biodiesel.

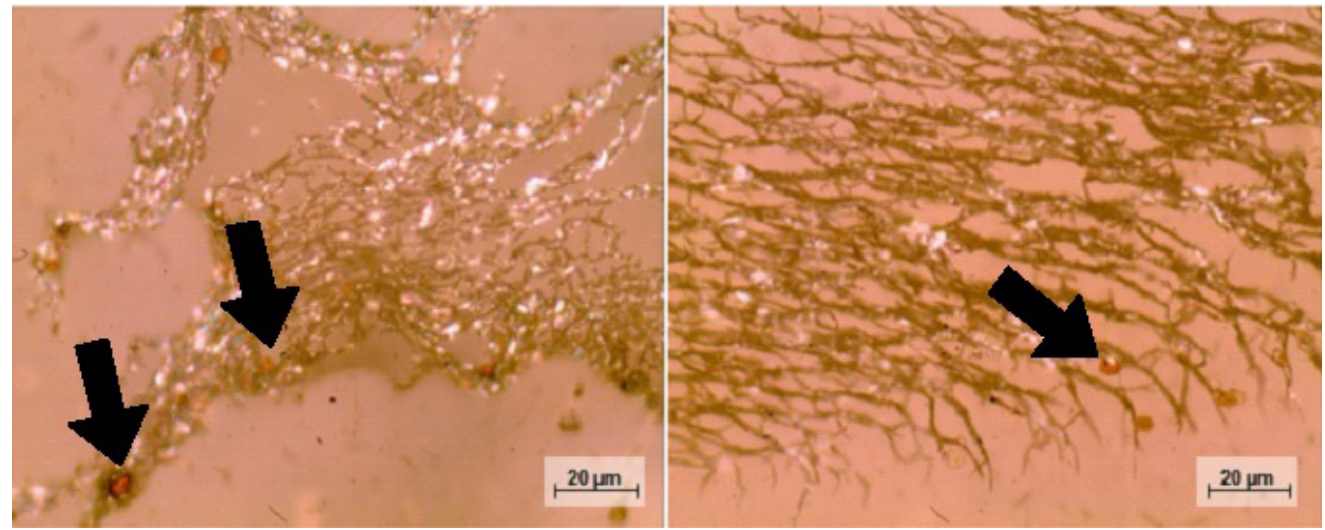

Figure 7. Contaminated blade with 2\% left and 5\% right. Source: Author's own elaboration.
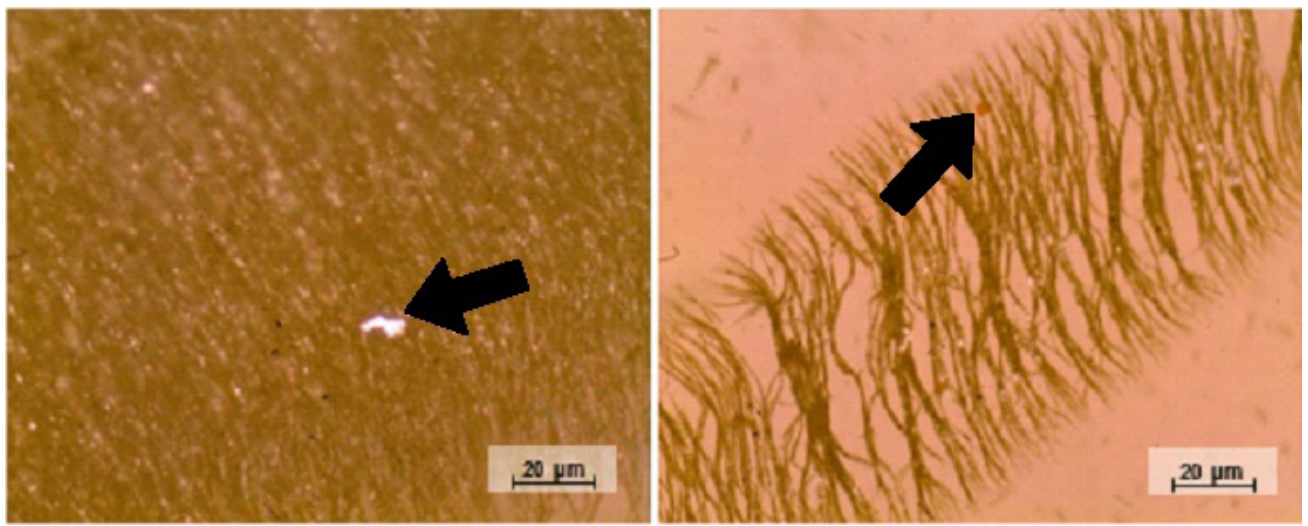

Figure 8. Contaminated blade with 2\% left and 5\% right. Source: Author's own elaboration. 


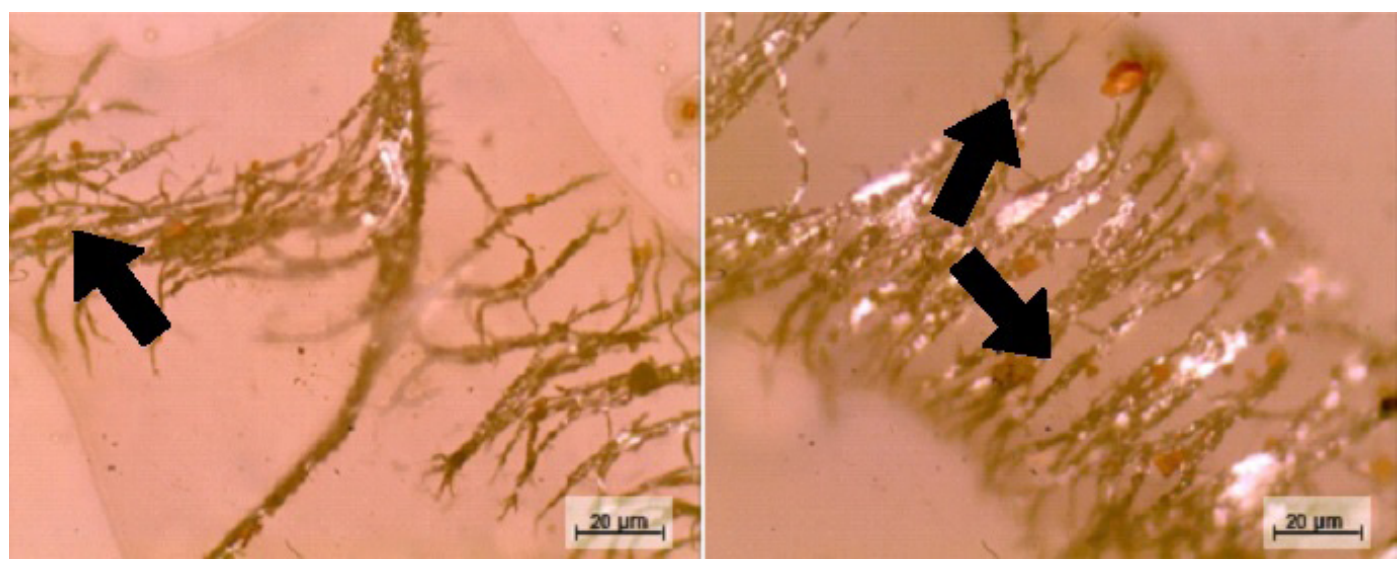

Figure 9. Contaminated blade with 2\% left and 5\% right. Source: Author's own elaboration.
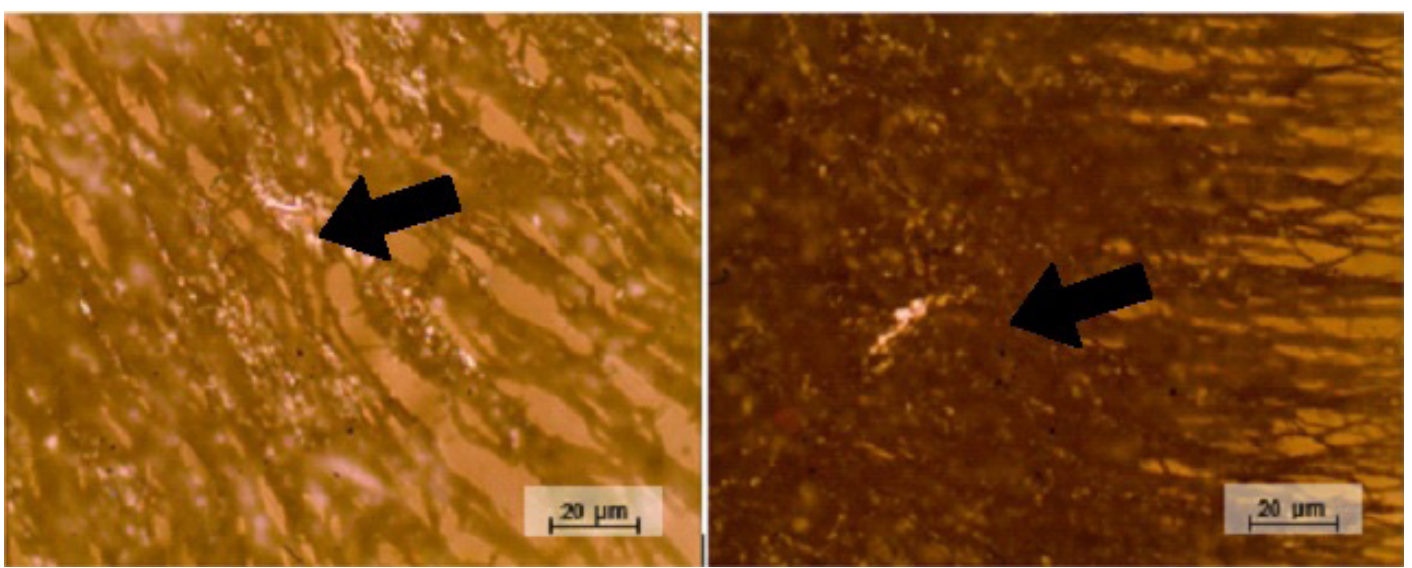

Figure 10. Contaminated blade with 2\% left and 5\% right. Source: Author's own elaboration.

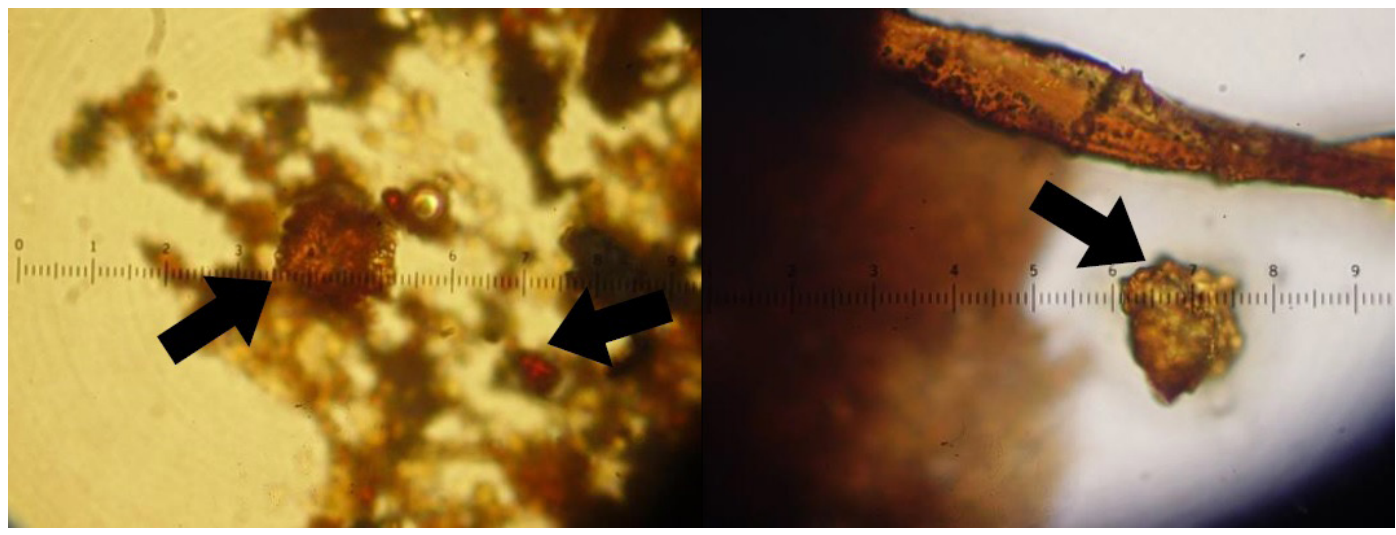

Figure 11. a) Ferrogram after heating with $2 \%$ contamination and $500 \mathrm{X}$ zoom on the left side; b) Ferrogram after heating with $5 \%$ contamination on the right side and 500X zoom. Source: Author's own elaboration.

- Load with the weight of $5 \mathrm{Kg}$ and $\mathrm{V}=1 \mathrm{~m} / \mathrm{s}$

The ferrograms in all Figures above have brownish particles (indicated by arrows) meaning they are medium alloy wear particles (material used in pins and disks).

Table 4 presents the flash point result.
As can be seen, the higher the contamination, the lower flash point is, as usual.

Table 5 shows the PQA values of the samples.

Table 6 shows the values of the elements found in each of the eight obtained samples, these samples were measured directly on the spectrometer device. 

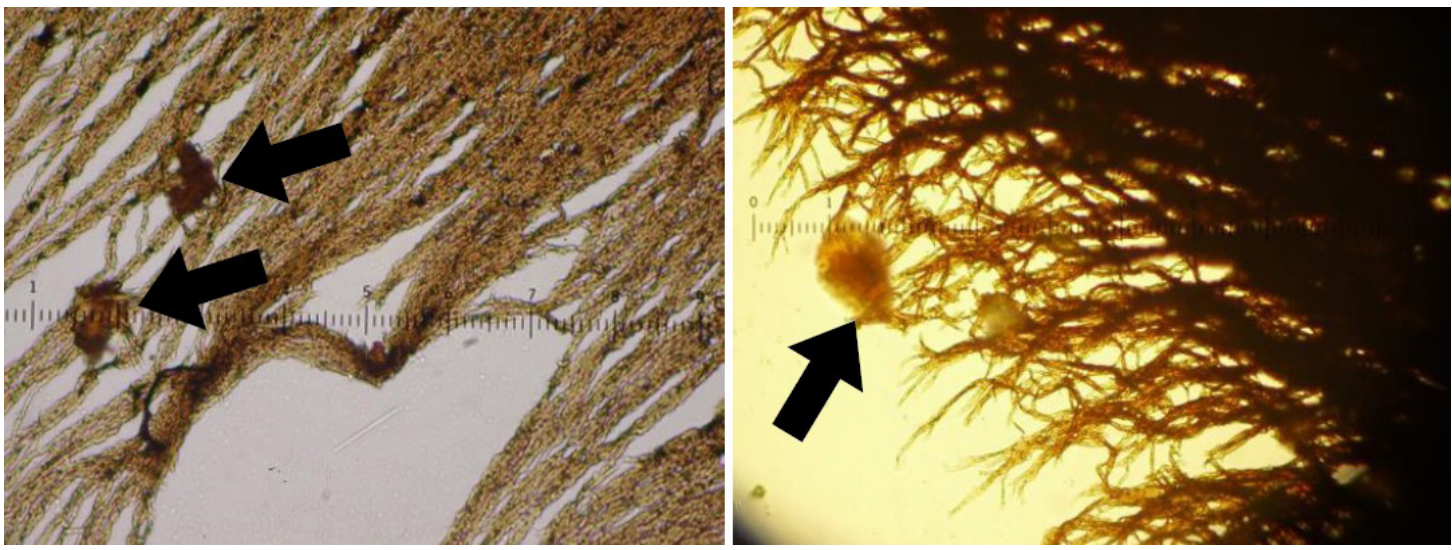

Figure 12. a) Ferrogram after heating with $2 \%$ contamination and $500 \mathrm{X}$ zoom on the left side; b) Ferrogram after heating with $5 \%$ contamination on the right side and 500X zoom. Source: Author's own elaboration.
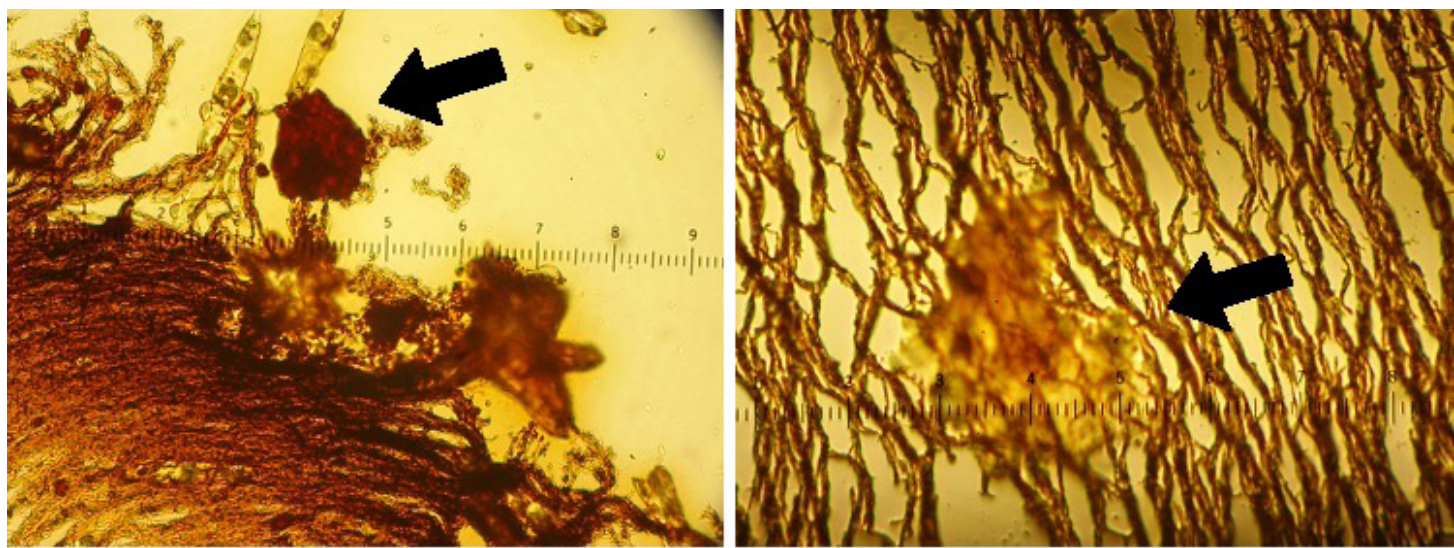

Figure 13. a) Ferrogram after heating with $2 \%$ contamination and $500 \mathrm{X}$ zoom on the left side; b) Ferrogram after heating with $5 \%$ contamination on the right side and 500X zoom. Source: Author's own elaboration.
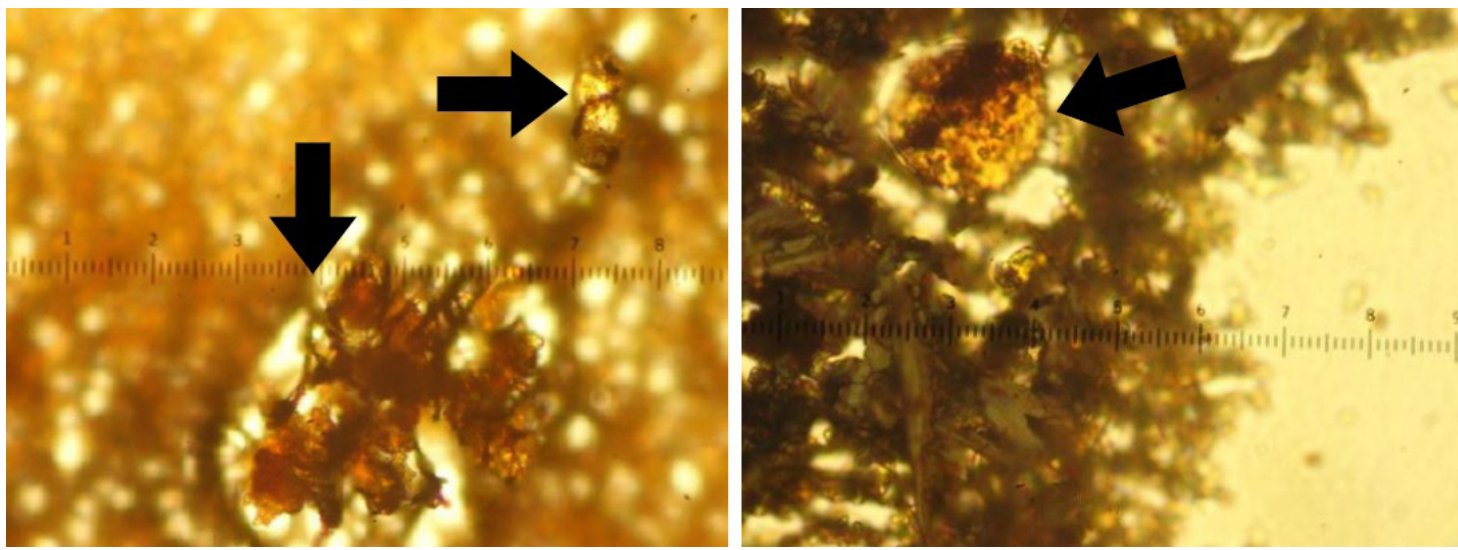

Figure 14. a) Ferrogram after heating with $2 \%$ contamination and $500 \mathrm{X}$ zoom on the left side; b) Ferrogram after heating with $5 \%$ contamination on the right side and 1000X zoom. Source: Author's own elaboration.

Tables 5 and 6 above show that the contamination of bio-diesel has a beneficial effect on the wear of the parts. Contamination of $5 \%$ was more beneficial than $2 \%$ for all combinations used.

Table 6 also shows that the amounts of $\mathrm{Cl}, \mathrm{Zn}, \mathrm{Ca}, \mathrm{P}$ and $\mathrm{S}$ decreased with the addition of contaminants and in the same proportion of the contaminant content added. These chemical elements are high as they are part of the composition of the lubricant additives. This decrease with contamination indicates a slight deterioration of the additives; also, a longer use leads to a higher decrease in such additives.

TBN values are expressed in Table 7. 
Table 4. Flash point values after contamination.

\begin{tabular}{cccccccc}
\hline B5 Boidiesel (Regular) & \multicolumn{2}{c}{$\begin{array}{c}\text { Vegetable Biodiesel } \\
\text { (Sunflower) }\end{array}$} & \multicolumn{2}{c}{ Animal Biodiesel (Fat) } & \multicolumn{2}{c}{ Vegetable + animal Biodiesel } \\
\hline $2 \%$ & $5 \%$ & $2 \%$ & $5 \%$ & $2 \%$ & $5 \%$ & $2 \%$ & $5 \%$ \\
\hline $220^{\circ} \mathrm{C}$ & $210^{\circ} \mathrm{C}$ & $224^{\circ} \mathrm{C}$ & $218^{\circ} \mathrm{C}$ & $234^{\circ} \mathrm{C}$ & $227^{\circ} \mathrm{C}$ & $222^{\circ} \mathrm{C}$ & $216^{\circ} \mathrm{C}$ \\
\hline
\end{tabular}

Source: Author's own elaboration.

Table 5. PQA values after all tests.

\begin{tabular}{lccccc}
\hline & Measurement 1 & Measurement 2 & Measurement 3 & Average & Standard deviation \\
\hline B5 & 130 & 132 & 132 & 131.3 & 1.2 \\
\hline B5 - 2\% & 125 & 124 & 124 & 124.3 & 0.6 \\
\hline B5 - 5\% & 122 & 123 & 121 & 122.0 & 1.0 \\
\hline Vegetable - 2\% & 120 & 120 & 119 & 117.0 & 0.6 \\
\hline Vegetable - 5\% & 117 & 116 & 118 & 109.7 & 1.0 \\
\hline Animal - 2\% & 110 & 110 & 109 & 107.3 & 0.6 \\
\hline Animal - 5\% & 107 & 108 & 116 & 115.0 & 0.6 \\
\hline $\begin{array}{l}\text { Animal + Vegetable } \\
-2 \%\end{array}$ & 115 & 113 & 113 & 113.0 & 0.0 \\
\hline $\begin{array}{l}\text { Animal + Vegetable } \\
-5 \%\end{array}$ & 113 & & & & \multirow{2}{*}{0.0} \\
\hline
\end{tabular}

Source: Author's own elaboration.

Table 6. X-ray spectrometer values.

\begin{tabular}{cccccccccc}
\hline .Elements & B5 & B5 - 2\% & B5-5\% & $\begin{array}{c}\text { Vegetable } \\
2 \%\end{array}$ & $\begin{array}{c}\text { Vegetable } \\
5 \%\end{array}$ & $\begin{array}{c}\text { Vegetable } \\
+ \text { Animal } \\
-2 \%\end{array}$ & $\begin{array}{c}\text { Vegetable } \\
+ \text { Animal } \\
-5 \%\end{array}$ & Animal 2\% & Animal 5\% \\
\hline $\mathrm{Fe}[\mathrm{mg} / \mathrm{kg}]$ & 1733.32 & 1731.8 & 1700.1 & 1245.1 & 1172.8 & 1170.4 & 1058.0 & 1007.5 & 998.6 \\
\hline $\mathrm{Cl}[\mathrm{mg} / \mathrm{kg}]$ & 500.3 & 489.9 & 466.2 & 507.0 & 529.5 & 506.2 & 505.4 & 384.3 & 285.8 \\
\hline $\mathrm{Zn}[\mathrm{Wt} \%]$ & 0.2107 & 0.2085 & 0.1835 & 0.2105 & 0.2083 & 0.1806 & 0.1784 & 0.1142 & 0.106 \\
\hline $\mathrm{Ca}[\mathrm{Wt} \%]$ & 0.880 & 0.8048 & 0.5880 & 0.6216 & 0.6352 & 0.7710 & 071697 & 0.5198 & 0.3652 \\
\hline $\mathrm{P}[\mathrm{Wt} \%]$ & 0.5002 & 0.4891 & 0.4587 & 0.4712 & 0.5295 & 0.0911 & 0.0943 & 0.4207 & 0.3183 \\
\hline $\mathrm{S}[\mathrm{Wt} \%]$ & 6.0144 & 5.9892 & 5.4944 & 5.6932 & 5.5001 & 5.2056 & 5.1922 & 5.0041 & 4.8167 \\
\hline $\mathrm{Sol}$
\end{tabular}

Source: Author's own elaboration.

Table 7. TBN value for each sample tested.

\begin{tabular}{lcc}
\hline & Contamination & TBN $[\mathrm{mg} / \mathrm{g}]$ \\
\hline Oil Lubrax SAE40 CF & Pure & 11.59 \\
\hline \multirow{2}{*}{ B5 } & $2 \%$ & 12.09 \\
\cline { 2 - 3 } & $5 \%$ & 12.38 \\
\hline \multirow{2}{*}{ Vegetable } & $2 \%$ & 15.32 \\
\hline \multirow{2}{*}{ Animal } & $5 \%$ & 14.80 \\
\hline \multirow{2}{*}{ Vegetable + Animal } & $2 \%$ & 15.83 \\
\cline { 2 - 3 } & $5 \%$ & 14.74 \\
\hline Source: Author's own elaboration. & $5 \%$ & 15.55 \\
\cline { 2 - 3 }
\end{tabular}

Table 7 shows the influence of the basicity, of contaminants in the lubricating oil, expressed in terms of the alkaline $\mathrm{KOH}$ reserve per gram of lubricating oil. The number is proportional to the injected amount of titrant.

The lubricating oil used in the tests has an alkaline $\mathrm{KOH}$ reserve of $11.6 \mathrm{mg} / \mathrm{g}$.

It is verified that when the oil is contaminated by vegetable and animal biodiesels, there is an increase in the alkaline reserve of the sample, presenting values up to $15 \mathrm{mg} / \mathrm{g}$. The biodiesel with the greatest effect on the total base number value is the $2 \%$ vegetable plus animal biodiesel contamination, which raises the alkaline reserve to $15.55 \mathrm{mg} / \mathrm{g}$.

Through the results obtained it is also observed that when the oil is contaminated with B5 diesel (regular) it presents an increase in the alkaline reserve as there is greater contamination, while all the others analyzed are the opposite, that is, the greater the contamination (in the proportions used), the lower the alkaline reserve.

It is noted here that acids from engine combustion decrease this alkaline reserve and were not considered in this work.

\section{Conclusion}

In the viscosity index test it is found that the contamination that acts for the benefit of lubrication is the $5 \%$ of animal biodiesel, since it is known that the higher the viscosity index the lower the influence of temperature. On the other hand, contamination by $5 \%$ of animal plus vegetable biodiesel, will act in the opposite way, impairing the lubrication performance of the engine, since it has a lower viscosity index than what would happen in natural B5 diesel system contamination.

The dispersion test came out as expected, pointing to no lack of lubricant dispersant additive in the system and no 
substantial improvement of the system after each contamination compared to natural contamination by B5 diesel.

The analytical ferrography, with and without heating of the ferrograms, showed no noticeable difference in between the wear particles formed and the types of contamination of the lubricating oil.

In the flash point test, which directly influences the combustion of the contaminated, the higher the contamination, the lower the flash point, as expected.

In PQA and X-ray tests, there is a beneficial effect of contamination on Lubricant lubricity, a fact observed by the decrease in PQ and Fe values in contaminated samples.

Still in the X-ray test, it is observed very slight decrease of the additives contents in relation to the uncontaminated lubricant. This decrease did not prevail over the lubricity provided by the addition of contaminants (bio lubricants) in the lubricant used.

Further analysis results in alkalinity, as it is known that when combustion occurs in the engine, combustion residues contaminate the lubricating oil, lowering its alkaline reserve. Since this aspect is already known, it is extremely important to consider the influence of contamination of each biodiesel on the lubricant. For this issue, the alkalinity test was performed on the oil after it has been contaminated by every type of biodiesel, which showed that not all contamination is harmful in relation to the original lubricating oil in this aspect, actually, the sample of $2 \%$ contamination by vegetable biodiesel proved to have the best result in this essay. It is important to note that the beneficial effect is due to contamination of the biodiesels in the lubricant prior to combustion, since the combustion products are acidic and not the biodiesels itself.

Therefore, this study proves that each type of contamination, vegetable or animal, in biodiesel, can improve some properties and worsen others.

From the results obtained, it can be concluded that the addition of biodiesel in diesel has its effects and that within the parameters of the tests used (hardness of pins and discs, sliding speed, proportion of biodiesel, lubricant recommended by the manufacturer of the internal combustion engine and type of this engine) there is no change that is harmful to both the engine and the lubricant itself.

The work presents possibilities for continuity. One of these possibilities is the comparison of results with those of other authors. For example, it is possible to use the hardness measurements of the pin and the disc to compare with the measurements of other authors, taking into account the proportionality of the distance traveled, the load used, the speed imposed and the type of biodiesel used. . The wear can also be theoretically obtained through equations and measurements of the depth of the wear rail.

\section{Aknowledgment}

The authors thank the Brazilian agencies FAPESP and CNPq for continuous support and UNIFEV (Votuporanga University Center) for supporting the publication fee.

\section{References}

1. Knothe G. "Designer" biodiesel: optimizing fatty ester composition to improve fuel properties. Energy Fuels. 2008;22:1358-64.
2. Booser ER. CRC handbook of lubrication and tribology. Volume 3: monitoring, materials, synthetic lubricants and applications. Boca Raton: CRC Press; 1994.

3. Shanta SM, Molina GJ, Soloiu V. Tribological effects os mineral oil lubricant contamination with biofuels: a pin-on-disk tribometry and wear study. Adv Tribol. 2011;2011:820795.

4. Castro VC. Lubricated sliding wear of SAE 1045 and SAE 52100 steel against alumina in the presence of biodiesel, diesel and a 50:50 blend of those fuels. Wear. 2016;368-369:267-77.

5. Fang HL, Shawn DW, Yamaguchi S, Boons M. Biodiesel impact on wear protection of engine oils. In: Powertrain \& Fluid Systems Conference; 2007 Oct; Rosemont. Proceedings. Warrendale: SAE International; 2007.

6. Thornton MJ, Alleman T, Luecke J, McCormick R. Impact of biodiesel fuel oil dilution on light -duty diesel engine operation. In: SAE International Power Train. Fuels and Lubricants Meeting; 2009 June; Florence. Proceedings. Warrendale: SAE International; 2009.

7. Lockwood FE, Dalley R. Lubricant analysis. In: Henry SD, Zorc TB, editors. ASM Handbook: friction, lubrication and wear technology. Metals Park: The Materials Information Society; 1992. p. 299-312.

8. Gonçalves AC, Cunha RC, Lago DF. Maintenance of a reducer by vibration and wear particles analysis. J Qual Mainten Eng. 2006;12(2):118-32.

9. Gonçalves AC, Padovese LR. 2010. Vibration and oil analysis for monitoring problems related to water contamination in rolling. In: 1st International Brazilian Conference on Tribology and 2nd International Tribology Symposium of IFToMM; 2010 Nov 24-26; Rio de Janeiro. Proceedings. Rio de Janeiro: ABM; 2010. p. 80-90.

10. Gonçalves AC, Padovese LR. Identification of lubricant contamination by biodiesel using vibration analysis and neural network. Ind Lubr Tribol. 2012;64:104-10.

11. Shumacher LG, Gerpen JV. Engine oil analysis of diesel engines fueled with 0. 1. 2. 100 percent Biodiesel. In: ASAE Annual International Meeting; 9-12 Jul 2000; Milwaukee. Proceedings. St. Joseph: American Society of Agricultural Engineers. 2000.

12. Fitch J. The agony of diesel engine oil particle counts. Practing oil analysis. March-april. p.2-5. 2005.

13. Geach AL. An automated approach to measuring fuel dilution in used engine oil. In: International Conference on Condition Monitoring; 21-25 Mar 1994; Swansea. Proceedings. Swansea: Pineridge Press. 1994.

14. ABNT: Associação Brasileira de Normas Técnicas. Critério de Classificação dos Aços, NBR NM 172/2000. Rio de Janeiro: ABNT; 2000.

15. Outa R, Chavarette FR, Mishra VN, Gonçalves AC, Roefero LGP, Moro TC. Prognosis and fail detection in a dynamic rotor using artificial immunological system. Eng Comput. 2020;37(9):3127-45. http://dx.doi.org/10.1108/EC-08-2019-035.

16. Barsari MAN, Shirneshan A. An experimental study of friction and wear characteristics of sunflower and soybean oil methyl ester under the steady-state conditions by the four-ball wear testing machine. J Tribol. 2019;141(4):044501. http://dx.doi. org/10.1115/1.4042390.

17. Khorshidnia $\mathrm{H}$, Shirneshan A. Investigating the tribological behavior of diesel-biodiesel blends with nanoparticle additives under short-term tests. J Adv Manuf Technol. 2019;12(3):19-24.

18. Barsari MAN, Shirneshan A. Investigation into the tribological properties of biodiesel-diesel fuel blends under the run-in period conditions. SAE Int J Fuel Lubr. 2019;12(2):143-9. http://dx.doi. org/10.4271/04-12-02-0009.

19. PETROBRAS. Lubrificantes: fundamentos e aplicações. Rio de Janeiro: PETROBRAS; 2009.

20. ABNT: Associação Brasileira de Normas Técnicas. ABNTNBR 05798: Produtos de petróleo - Determinação do índice de basicidade por titulação potenciométrica com ácido perclórico. Rio de Janeiro: ABNT; 2009. 